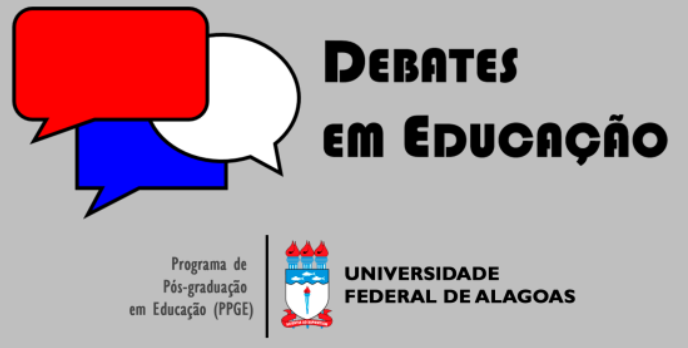

ISSN Eletrônico 2175-6600

Vol. 10 | No. 21 | Maio/Ago. | 2018

Rosilânia Macedo Silva

Universidade de Aveiro (UA - Portugal) rosilaniamacedo@hotmail.com

\section{A ORGANIZAÇÃO DA GESTÃO DEMOCRÁTICA NAS ESCOLAS BRASILEIRAS E PORTUGUESAS: UMA ANÁLISE NOS MARCOS LEGAIS}

\section{RESUMO}

Este artigo traz um recorte dos resultados da pesquisa desenvolvida no âmbito do mestrado em Ciências da Educação na área de Administração e Políticas Educativas, na Universidade de Aveiro/Portugal. Objetivou analisar textos legais vigentes homologados no Brasil e em Portugal, que tratam da gestão escolar. O estudo enquadrado na abordagem qualitativa se estruturou nas categorias: princípios, organização, composição e objetivos. Este artigo, em específico, trata da categoria organização. Desenvolvido com a pesquisa bibliográfica e documental, as análies na legislação dos dois países, nos apontou, mesmo com a distância geográfica, muita homogeneidade entre a legislação, deflagrando grandes influências globais.

Palavras-chave: Gestão democrática. Organização. Legislação educacional.

\section{THE ORGANIZATION OF DEMOCRATIC MANAGEMENT IN BRAZILIAN AND PORTUGUESE SCHOOLS: AN ANALYSIS IN LEGAL FRAMEWORKS}

\section{ABSTRACT}

This article brings a summary of the results of the research carried out within the scope of the Masters in Educational Sciences in the area of Administration and Educational Policies, University of Aveiro / Portugal. It aimed to analyze current legal texts approved in Brazil and Portugal, which deal with school management. The study framed in the qualitative approach was structured in the categories: principles, organization, composition and objectives. This article, in particular, deals with the organization category. Developed with the bibliographical and documentary research, the analysis in the legislation of the two countries, pointed us, even with geographical distance, much homogeneity between the legislation, triggering great global influences.

Keywords: Democratic management. Organization. Educational legislation.

Submetido em: 27/05/2018

Aceito em: 28/07/2018

DOI: $10.28998 / 2175-6600.2018 v 10 n 21 p 16-30$ 


\section{INTRODUÇÃO}

O movimento global proporciona uma educação cada vez mais com políticas estatais homogêneas (AZEVEDO, 2007), incidindo sobre os Estados fragilização quanto sua autonomia frente ao gerencialismo de organismos internacionais e de países hegemônicos (KRAWCZYK, 2008; MARINIS, 2008). Estas instituições sob o poder de indicadores e comparações tendem a proporcionar a elaboração de legislação educacional semelhante entre países.

Uma área específica onde há influências mais evidentes e reguladas por normativos legais é a gestão escolar, no ensino básico. Os sistemas de ensino em diversos lugares do mundo adotaram a gestão escolar com a participação da comunidade e descentralização dos recursos financeiros e administrativos, visando a autonomia das ações das escolas. Essa é a realidade tanto no Brasil como em Portugal.

Nessa perspectiva, este trabalho que é oriundo da dissertação de mestrado defendida no âmbito da área de Administração e Políticas Educativas, a partir da abordagem qualitativa (AMADO, 2009; CARRANCHO, 2005), objetivou a análise documental (CARDOSO; ALARCÃO e CELORICO, 2010; ESTEVES, 2006) na legislação dos dois países, onde estabeleceu-se análises/comparações entre elas (MARTINS, 2011; SCHNEIDER ; SCHMITT, 1998) considerando para este artigo, a categoria organização.

Este encontra-se estruturado, além desta introdução, conclusões e referências, do referencial teórico, onde fazemos uma breve discussão acerca da globalização e suas influências na elaboração da legislação dos países, sobretudo, na educação, incidindo no modelo de organização do gerenciamento escolar. Seguimos com o referencial teórico, fazendo breve discussão sobre gestão escolar nas escolas, sob o direcionamento da legislação. Continuamos com a descrição da metodologia, onde apontamos o desenvolvimento da pesquisa. Enfim apresentamos o resultado dos estudos, quanto à análise da legislação brasileira e portuguesa frente a organização da gestão democrática.

\section{A GLOBALIZAÇÃO NA LEGISLAÇÃO EDUCACIONAL}

As influências "integram os chamados efeitos da globalização" que regulam os Estados (BARROSO, 2004, p. 15). Se estes enquanto instituições organizam a "ação coletiva dos cidadãos de cada Estado-nação, através da Constituição Nacional” (BRESSER-PEREIRA, 2004, p. 8) e de seus derivados (leis, decretos-leis, normas), compreende-se ser perfeito o sistema jurídico do país para a implantação da regulação de 
concepções externas, principalmente, em países considerados democráticos, nos quais a elaboração dos mecanismos legais é realizada a partir de representações do povo.

Como dito, a regulação elaborada pelo Estado pode ser entendida como obra não exclusiva dele, portanto, a legislação vivenciada na escola pode estar facultada às "forças maiores", pois a "globalização, nas suas várias facetas, veio vincar uma crise de legitimação dos Estados nacionais, sobretudo pelo modo como põe em causa e relativiza o papel das soberanias nacionais" (AZEVEDO, 2007, p. 99). Neste contexto, é comum a afirmação de que os organismos internacionais estariam presentes diante das elaborações das leis, através de "um processo de indução externa" (KRAWCKY, 2008, p. 3). Esta prática é denominada como regulação transnacional (AZEVEDO, 2007; BARROSO, 2004). No dizer de Barroso (2004, p. 15), trata-se de:

conjunto de normas, discursos instrumentos ... que são produzidos e circulam nos fóruns de decisão e consultas internacionais, no domínio da educação, e que são tomadas pelos políticos, funcionários ou especialistas nacionais, como "obrigação" ou "legitimação" para adoptarem ou proporem decisões ao nível do funcionamento do sistema educativo.

Quase sempre com uma carga polêmica, a elaboração de leis, sobretudo, as educacionais, se manifestam através de uma certa movimentação de concepções e posicionamentos de pessoas pertencentes a grupos específicos na sociedade, quer seja por influência direta ou não dos organismos internacionais. Quer seja por consciência ou não. "Neste contexto, o conhecimento é externalizado, sobretudo pelos discursos dos actores, e as constelações de conhecimentos são determinadas pelas estruturas das redes sociais, definidas pela circulação dos actores em diferentes cenas da acção pública", afirma Barroso (2009, p. 1000). Desta forma, os indicadores internacionais sobre educação ganham forma de lei a partir das personagens que compõem a educação e por circunstâncias podem fazer-se prevalecer as suas ideias num processo legislativo sob a influência já discutida. Barroso (2009, p. 1001) denomina de "advocacy coalitions" (coligações de causas), a mobilização destes conhecimentos e são selecionados conforme os "interesses partilhados pelo grupo e com a sua eficácia para manipular o debate e influenciar os diversos actores (no Parlamento, no Ministério da Educação, nas escolas, na imprensa, nos sindicatos, nas universidades, etc.).

Enquanto escola, a implantação se dá na dinâmica da gestão escolar através dos aspectos da participação, autonomia e descentralização e podemos ressaltar essa problemática com Ball e Youdell (2007, p. 11) quando afirmam que uma "range of policy tendencies that can be understood as forms of privatization are evident in the education 
policies of diverse national governments and international bodies. Some of these forms are named as privatization but in many cases privatization remains hidden"1.

A legislação, muitas vezes elaborada e mediada pelos agentes acima discutidos e sancionada pelo Estado, tende a afetar a sociedade, alterando os comportamentos das instituições as quais se destina. Por mais que se diga que leis são "letras mortas", e que exista uma infidelidade normativa, como nos fala Lima (1991), a legislação visível ou invisivelmente, indireta ou diretamente, é aplicada no âmbito escolar. A escola é um espaço burocrático e por assim ser, pratica as recomendações ou imposições legais reguladas e regulamentadas, senão em abrangência, em partes.

\section{BREVE REFLEXÃO SOBRE GESTÃo E DIREÇÃO NO ÂMBITO ESCOLAR}

No processo de globalização a gestão em maneira geral, é entendida como aspecto essencial como fórmula para o sucesso, tornando-se o "carro chefe" dos órgãos e instituições públicos (KRAWCZYK, 2002). Diante disto se faz fundamental entender o significado de gestão frente ao de direção, ambos tão difusos e nem sempre compreendidos. Lima (1988, p. 160) explica que direção e gestão, são "efetivamente distintas e representam diferentes funções administrativas abrangidas pelo conceito mais amplo de administração". Tendo a consciência de que direção e gestão não tratam-se da mesma finalidade, compreender-se-á melhor o discernimento deste trabalho que se prolongará nas discussões sobre esta última. Neste intuito, busquemos Formosinho (1988, p. 82) que também esclarece a direção e gestão como partes da administração e afirma que direção refere-se "predominantemente à formulação de políticas e estratégias ou à sua adaptação. A gestão refere-se, sobretudo à implementação dessas políticas e estratégias".

Notemos que a direção é mais abrangente e está para as atribuições no âmbito mais político no qual se definem as políticas e as orientações que devem ser desenvolvidas pela gestão. Deste modo, a gestão compõe a parte do fazer, executar o definido pela direção. Em suma, a gestão compõe a parte técnica das atividades de uma instituição (LIMA, 1988) a qual Dalbério (2008, p. 3) afirma ser o "entendimento de comunicação pelo envolvimento coletivo, por meio do discurso e do diálogo". Diante disto, a gestão, técnica da administração, é facultada à democracia. A democracia é uma "organização política que

\footnotetext{
1 "A variedade de tendências políticas que podem ser entendidas como formas de privatização são evidentes nas políticas de educação de diversos governos nacionais e organismos internacionais. Algumas dessas formas são nomeadas como privatização, mas em muitos casos a privatização permanece oculta ".
} 
reconhece a cada sujeito como membro da comunidade, o direito de participar da direção e da gestão dos assuntos públicos", considera Dalbério (2008, p. 3). Este conceito consonante a muitos outros é o que se espera entender e vivenciar em sociedade. No entanto, Lima (2005, p. 5) compreende democracia como conceito que possui várias práticas e "faz parte de um movimento ideológico que distorce as ideias quando afirma que todos são iguais na defesa dos direitos democráticos," parecendo existir um único conjunto de homens e de defesa dos direitos democráticos", não existindo separações políticas e concepções de governos senão o democrático.

\section{METODOLOGIA}

\subsection{Enquadramento da pesquisa}

O paradigma é a fundamentação filosófica e epistemológica que o investigador deve escolher quando das teorias, metodologias e técnicas a desenvolver na investigação (AMADO, 2009). Ele "proporciona los medios apropriados y exclusivos de escoger entre los tipos de métodos", no entendimento de Cook e Reichardt (2000, p. 30). Sendo assim, esta pesquisa fundamentou-se no paradigma qualitativo e, logicamente, na abordagem qualitativa por serem os dados recolhidos "em formas de palavras" (BOGDAN; BIKLEN, 1991, p. 48) e se assentar numa visão da realidade (ou problema) sobre o objeto de estudo, no caso, análises da legislação brasileira e portuguesa, sem as "isolar do contexto natural (histórico, socioeconómico e cultural)" onde procurou-se "atingir a sua "compreensão"' (AMADO, 2009, p. 70). Deste modo, como ocorre em pesquisas qualitativas, inferiu-se carga de valores e interpretações (COOK; REICHARDT, 2000; FOSTER, 1996). Como a ação de analisar documentos escritos denota valor e princípios, não eliminou-se totalmente a carga de subjetividade, característica eminentemente da abordagem qualitativa (AMADO, 2009; COOK; REICHARDT, 2000; FLICK, 2005; NEVES, 1996), ela se fez presente. No entanto, como aconselham Foster (1996) e Amado (2009) houve esforço no sentido de buscar a fidelidade aos dados.

\subsection{O percurso da pesquisa}

O início fez-se através da pesquisa bibliográfica onde buscou-se compreender um arcabouço de obras sobre o assunto, propiciando a revisão do "tema sob diferentes enfoques e conclusões" (VASQUES, 2008, p. 08). Então, a revisão de literatura, "corpo de 
conhecimento já produzido (CARDOSO; ALARCÃO e CELORICO 2010, p. 15), deu-nos sustentação para o desenvolvimento deste trabalho por nos permitir conhecer as contribuições científicas sobre o tema, "constituído principalmente de livros, artigos de periódicos e de material disponibilizado na Internet” (SILVA; MENEZES, 2001, p. 21).

Após esta etapa, realizou-se a coleta de dados na perspectiva de uma pesquisa documental onde caracterizou-se na recolha da legislação brasileira e portuguesa. Os dados compilados escritos são contemporâneos (VASQUES, 2008) e em vigor. Assim, o corpus de dados constam de uma coletânea de legislação do âmbito nacional dos dois países, para este artigo, se constituem em constituições, leis, decretos-leis, decretos-leis, planos e, no caso do Brasil, quando de aspectos mais específicos, recorremos aos cadernos do Ministério da Educação e Cultura, que trazem resumos da realidade dos sistemas de ensino em todo o território brasileiro e servem igualmente como referências normativas para as redes de ensino estadual e municipal, e foram reexaminadas "com vistas a uma interpretação nova ou complementar" (NEVES, 1996, p. 3).

Sendo a legislação, objeto de estudo, considerando a necessidade de limitar o campo a ser investigado e no sentido de "reconfigurar o material ao serviço dos determinados objectivos de investigação" (ESTEVES, 2006, p. 109) criaram-se quatro categorias a serem analisadas e "para serem aplicadas ao material" (FLICK, 2005, p. 193) investigado. As categorias neste estudo foram definidas como princípios, organização, composição e objetivos da gestão democrática escolar, implantadas nas escolas públicas de ensino básico nos países em questão. Ao serem definidas as categorias, efetivaram-se procedimentos clássicos de análise do material escrito (FLICK, 2005, p. 193), a análise dos documentos. Neste artigo em específico, trataremos da categoria organização.

Por se tratar de um estudo em que são envolvidos dois países sob objetivos iguais a serem investigados, foi impossível não comparar. Isto porque, no desenvolver do trabalho houve identificações de "continuidades e descontinuidades, semelhanças e diferenças", atitudes em uma pesquisa que são características do método comparativo, como afirmam Schneider e Schmitt (1998, p. 49).

\section{ANÁLISE DO OBJETO DE ESTUDO}

Portugal possui mais precisamente o governo central para emitir legislação reguladora. No Brasil os governos locais também emitem legislação reguladora, tendo os conselhos de educação e órgãos públicos responsáveis pela legislação regulamentadora, como os pareceres, resoluções e portarias. No caso dos pareceres, no Brasil, geralmente, 
é emitido quando da lei já homologada com objetivo de esclarecê-la e/ou para dar direcionamento à uma situação particular. Em Portugal este documento é mais utilizado para recomendar mudanças quando da elaboração de DLs. Isto foi o que ocorreu quando do Projeto do DL 177/2007 desencadeante no DL 75/2008² que trata da autonomia, administração e gestão das escolas. João Barroso (2008), Natércio Afonso (2008) e o Conselho Nacional de Educação, emitiram parecer sobre o referido Projeto.

Portugal possui mais decretos-leis que propriamente leis. As leis são consensuais, oriundas de grandes debates e com o envolvimento de parlamentares. Os DLs, como acima já dito, passam pelo crivo de pessoas de notórios saber na sociedade. No Brasil, é mais comum a homologação de leis. Os decretos no Brasil possuem conotações não democráticas por serem homologados por chefes executivos, geralmente, sem a devida apreciação de outros poderes.

Ressaltemos que neste artigo serão analisadas a legislação homologada por Brasil e Portugal que relacionem-se com a gestão democrática escolar, considerando as categorias acima citadas.

Verifica-se que a complexa estrutura brasileira de ensino não anula a condição dos dois países estarem em pé de igualdade. Ambos possuem órgãos desconcentrados e a descentralização incide exatamente nas federações menores do Estado, os municípios. Sendo estes responsáveis igualmente pela pré-escola e sob a regulamentação e acompanhamento dos Conselhos Municipais de Educação, conforme DL 7/2003. A diferenciação concerne na atribuição de diretor escolar para as instituições. No caso brasileiro, é comum cada escola de educação pré-escolar possuir a mesma organização das outras duas etapas de ensino. Em Portugal, o DL 144/2008 determina um coordenador para estas escolas, devendo ser administradas e gestadas pelo agrupamento em que pertencem. Note-se que com apenas um sistema, a legislação portuguesa coesa o número de diretores, como o número de participantes na gestão. Ou seja, no Brasil, em geral, há um diretor/gestor para cada instituição, enquanto em Portugal há um para várias escolas, sendo portanto, número reduzido, logo, controle facilitado.

No nosso entendimento a presente análise serve como norte para a compreensão das análises que se seguirão neste capítulo.

\footnotetext{
2 O site oficial do Ministério da Educação português consta da informação de um novo decreto a substituir este. A informação intitulava-se: Concluídas negociações sobre regime de autonomia, administração e gestão escolar.
} 
5.1 A organização da gestão democrática nas escolas brasileiras e portuguesas

Compreendemos por organização da gestão democrática a estruturação da governação escolar enquanto órgãos internos responsáveis pela escola e desenvolvimento dos princípios organizativos.

Nota-se que o texto da LDBEN (art. 14, II) é claro quando orienta a "participação das comunidades escolar e local em conselhos escolares ou equivalentes" (quadro 1). Percebese, entretanto, que a $\operatorname{LBSE}(48,4)$ assegura às escolas a criação de "órgãos próprios, para os quais são democraticamente eleitos os representantes de professores, alunos e pessoal não docente" (quadro 1). No entanto, a lei não define o nome do órgão a ser criado ou se seriam as escolas ou não a definirem a nomenclatura e organização dele.

Um fato que chama a tenção é a ausência da nomenclatura gestor ou diretor nas leis reguladoras de topo nos dois países, constituição e lei de bases (quadro 1). Nota-se alguma intencionalidade para a ausência dessa personagem, como se a intenção primeira fosse a escola gestada por órgãos colegiados. Isto, no nosso entender ficar patente no entendimento do MEC, no caso brasileiro:

A questão central é que as leis firmam valores, não criam cultura. A efetivação do novo princípio da gestão democrática requer um processo instituinte de uma nova cultura de gestão escolar. Gestão que não se confunde mais com o gestor, com a centralização nas mãos do diretor, mas que passa a ser vista como um projeto coletivo, que institui uma organização colegiada (BRASIL, 2004b, p. 52).

Se a intencionalidade da ausência do diretor existiu, prevaleceu a tradição. O diretor ou gestor é figura que compõe a organização da gestão democrática nos dois países. Normativos posteriores à Constituição e Lei de Bases, trouxeram-no à nomenclatura no texto, ao exemplo do PNE/2001 e DL 75/2008 (quadro 1). Assim, a organização da gestão democrática tanto no Brasil como em Portugal, é edificada na figura do diretor/gestor e em órgãos colegiados. 
Quadro 1 - Organização da gestão democrática

\begin{tabular}{|c|c|}
\hline Brasil & Portugal \\
\hline \multicolumn{2}{|c|}{ Texto legal } \\
\hline LDBEN & LBSE \\
\hline \multirow{3}{*}{$\begin{array}{l}\text { Art. 14. Os sistemas de ensino } \\
\text { definirão as normas da gestão } \\
\text { democrática do ensino público na } \\
\text { educação básica, de acordo com as } \\
\text { suas peculiaridades e conforme os } \\
\text { seguintes princípios: } \\
\text { II - participação das comunidades } \\
\text { escolar e local em conselhos } \\
\text { escolares ou equivalentes. }\end{array}$} & $\begin{array}{l}\text { Art. 48ㅁ, } 1 \text { - O funcionamento dos } \\
\text { estabelecimentos de educação e } \\
\text { ensino, nos diferentes níveis, orienta- } \\
\text { se por uma perspectiva de integração } \\
\text { comunitária, sendo, nesse sentido, } \\
\text { favorecida a fixação local dos } \\
\text { respectivos docentes. }\end{array}$ \\
\hline & $\mathrm{DL}-75 / 2008$ \\
\hline & $\begin{array}{l}2 \text { - São órgãos de direcção, } \\
\text { administração e gestão dos } \\
\text { agrupamentos de escolas e escolas } \\
\text { não agrupadas }\end{array}$ \\
\hline
\end{tabular}

Fonte: Autora

Estes órgãos são muito valorizados na gestão dos dois países. Portugal possui três na organização colegiada definidas pelo DL 75/2008, artigo 21: a) O conselho geral; b) $O$ director; c) $\mathbf{O}$ conselho pedagógico; d) $\mathbf{O}$ conselho administrativo.

Como a lei brasileira faculta o nome do órgão colegiado, os sistemas de ensino deram nomes variados. Segundo o MEC (BRASIL, 2004a) são "Associações de pais, mestres e comunitários, Conselho escolar, Colegiado escolar, Associação de apoio à escola, Conselho de escola, conselho deliberativo escolar e Comitê comunitário" (pp. 4748). Um por escola.

À estruturação da organização escolar no caso exclusivo de Portugal, agrega-se diretores adjuntos (DL, 75/2008) sendo o número desta função definida pelo quantitativo de alunos matriculados, conforme Despacho n.ำ 18064/2010 do Ministério da Educação. Na realidade brasileira há os adjuntos ou vice-diretores. O número destes por escola depende da legislação local.

A organização da gestão escolar independentemente da quantidade de colegiados e das nomenclaturas tende a possuir princípios básicos que norteiam-na. Neste entendimento, pretendemos averiguar os instrumentos da organização da gestão democrática.

\subsection{Instrumentos de organização da gestão democrática}

Instrumentos de organização da gestão democrática no nosso entendimento são os documentos norteadores da gestão (quadro 2). Em princípio construídos coletivamente 
entre escola e comunidade sob o objetivo da organização das ações, administrativas, financeiras e pedagógicas da escola.

Quadro 2 - Instrumentos de organização da gestão democrática

\begin{tabular}{|c|c|}
\hline Brasil & Portugal \\
\hline \multicolumn{2}{|c|}{ Texto legal } \\
\hline LDBEN & DL n 75/2008 \\
\hline $\begin{array}{l}\text { Art. } 14 . \\
\text { I - participação dos profissionais da } \\
\text { educação na elaboração do projeto } \\
\text { pedagógico da escola; } \\
\text { Regimento interno das escolas }\end{array}$ & $\begin{array}{l}\text { Artigo 9. } . \\
1 \text { - O projecto educativo, o } \\
\text { regulamento interno, os planos anual } \\
\text { e plurianual de actividades e o } \\
\text { orçamento constituem instrumentos } \\
\text { do exercício da autonomia de todos } \\
\text { os agrupamentos de escolas e } \\
\text { escolas não agrupadas, sendo } \\
\text { entendidos para os efeitos do } \\
\text { presente decreto -lei } \\
2 \text { - São ainda instrumentos de } \\
\text { autonomia dos agrupamentos de } \\
\text { escolas e das escolas não } \\
\text { agrupadas, para efeitos da respectiva } \\
\text { prestação de contas, o relatório anual } \\
\text { de actividades, a conta de gerência e } \\
\text { o relatório de auto-avaliação, sendo } \\
\text { entendidos para os efeitos do } \\
\text { presente decreto-lei. }\end{array}$ \\
\hline
\end{tabular}

Fonte: Autora

Percebe-se que o sistema português consta de maior número de instrumentos e bem melhor definidos que os brasileiros. Este fato torna-se patente, considerando que são os sistemas de ensino brasileiro que devem melhor definir como e com que a gestão democrática deve ser desenvolvida nas escolas, no entanto, não podem deixar de possuir os dois instrumentos definidos em lei. Por assim ser, o MEC (BRASIL, 2011, p. 9) ensina que o "projeto político pedagógico contempla a organização de uma Educação Democrática" logo, nenhuma rede de ensino pode rejeitá-los.

Ressalte-se que estes instrumentos são a oportunidade que as escolas possuem para configurar-se em célula única. Eles permitem à escola definirem a sua filosofia de trabalho e metas a conquistar, em consonância com os partícipes e a realidade local, quando os órgãos desconcentrados não impõem um modelo único a ser seguido. No caso português, enquanto as escolas agrupadas vivenciam regimento e projeto educativo do agrupamento. Isto significa dizer que as escolas portuguesas agrupadas correm o risco de terem instrumentos de organização adversos à sua realidade e objetivos. Em consonância a isto, o MEC português entende ser objetivo dos agrupamentos de escolas, o favorecimento do "desenvolvimento de um projecto educativo comum, articulando níveis e ciclos de ensino distintos" (Resolução 44/2010). 
Na nossa interpretação, projeto educativo estar para o projeto político pedagógico e os planos anuais e o orçamento para o PDE, PDDE e outros programas a nível federal. Note-se quão semelhante andam os dois países, mesmo quando aparentam serem diferentes.

\section{CONSIDERAÇÕES FINAIS}

Como vimos, a escola pública tem sido submetida a uma multiplicidade de medidas e reformas a nível de sua gestão escolar sob a pressão de ditames do processo de globalização no qual há um "contexto controverso entre os valores da cidadania e da escola democrática e os valores gerencialistas" (TORRES;PALHARES, 2009, pp. 79-80). Estes valores tanto no Brasil como em Portugal são instituídos em leis, os primeiros explícitos e os segundos implícitos nas legislações que normatizam a gestão democrática escolar.

Considerando o posto nesta conclusão e nas análises desenvolvidas, chegamos ao entendimento final de que:

- As semelhanças entre Brasil e Portugal superam as diferenças;

- Os princípios organizativos homogêneos nos dois países são controlados pelo poder central no sentido de serem aplicados conforme as concepções do processo global;

- A nomenclatura "diretor" ganha ênfase em detrimento do "gestor", denotando que aquele cargo deve ser mais político e autônomo, como também, atribui-se mais autoridade a função;

- Os princípios organizativos preceituados na legislação referentes à gestão escolar democrática têm valores implícitos em prol da colaboração da rede privada na escola pública e financiamento da escola pública em empresas privadas.

Se a educação deixou de ser domínio doméstico (país) para ser um domínio global, ela pode fazer um caminho inverso: sair do domínio global para retornar ao local.

Compreende-se que a limitação deste trabalho centra-se na impossibilidade da realização de entrevistas com personagens brasileiras e portuguesas que representam a gestão democrática, como diretores/gestores e representantes de órgãos colegiados escolares. Isto se deu em decorrência da limitação do tempo e de recursos financeiros escassos. No entanto, com o que se conseguiu produzir, espera-se que possa servir de esclarecimentos e reflexões sobre o assunto com também de questionamentos para investigações sucessivas. 


\section{REFERÊNCIAS}

AFONSO, N. A reformada administração escolar-abordagem em análise organizacional. Lisboa: Instituto de inovação educacional, 1994.

AMADO, J. Introdução à investigação qualitativa em Educação (provas de agregações na Universidade de Coimbra). Univerisdade de Coimbra: Coimbra, 53-96, 2009.

AZEVEDO, J. Sistema educativo: Ensaio sobre a regulação transnacional de educação. Vila Nova de Gaia: FML, 2007.

BALL, S. Performidade, privatização e os pós-estado do bem-estar. Revista Educação, 25, 1105-1126, 2004.

BALL, S., \& YOUDELL, D. Hidden privatisation in public education. Institute Education. 2007.

BARROSO, J. A regulação da educação como processo compósito: tendências e desafios. In J. Costa, A. Neto-mendes, A. Ventura \& (Orgs.) (Eds.), Políticas e gestão local da educação. Atas do III Simpósio sobre organização e gestão escolar (pp. 1322). Aveiro: Universidadede Aveiro, 2004.

. J. A utilização do conhecimento em política: $O$ caso da gestão escolar em Portugal. Educação e Sociedade, 30, 987-1007, 2009.

BRASIL. Constituição da República Federativa do Brasil de 1988. (1998). Brasília. Recuperado em abril 2007, 1989.

Programa de fortalecimento nacional dos conselhos escolares. Brasília: $\overline{M E C}, 2004 a$

Conselhos escolares: uma estratégia de gestão democrática de gestão democrática de educação pública. Brasília: MEC, 2004b.

Projeto integrador: formação continuada de formação de conselheiros municipais de educação. 5. Brasília: MEC, 2011. 
. Lei no 9394/96. Dispõe sobre as Diretrizes e Bases da Educação Nacional.

Brasília: MEC, 1996

Lei no 10172/01. Dispõe sobre o Plano Nacional de Educação (2001/2011). Brasília: Gabinete Civil, 2001.

BOGDAN, R. ; BIKLEN, S. Investigação qualitativa em educação - Uma introdução à teoria e aos métodos (m. j. albes, s. b. baptista \& t. m. baptista, Trans.). Porto: Porto, 1991.

BRESSER-PEREIRA, L. Instituições, bom Estado e reforma de gestão pública. In BIDERMAN, P. A. (Orgs.) (Eds.). Economia do Setor Público no Brasil. São Paulo: Campus Elsevier, 2004, p 3-15.

CARDOSO, T., ALARCÃO, I., ; CELORICO, J. A. Revisão da literatura e sistematização do conhecimento. Porto: Porto Editora, 2010.

COOK, T. D. ; REICHARDT, C. S. Métodos cualitativos y cuantitativos en investigación evaluativa (G. Solana, Trans.). Madrid: Morata, 2000.

DALBÉRIO, M. C. B. Gestão democrática e participação na escola pública. Revista Iberoamericana de Educação, 3-25, 2008.

DALE, R. Globalização e educação: demonstrando a existência de uma "cultura mundial comum" ou localizando uma "agenda globalmente estrutural para a educação"? .

Educação e Sociedade, 25, 432-460, 2004.

ESTEVES, M. Análise de Conteúdo Fazer investigação: Contributos para a elaboração de dissertação e teses (pp. 105-126). Porto: Porto, 2006.

FLICK, U. Métodos qualitativos na investigação científica (A. Parreira, Trans.). Lisboa: Monitor, 2005.

FORMOSINHO, J. (1988). Princípios para a organização e administração da escola portuguesa. In M. d. Educação (Ed.), A gestão do sistema escolar: Relatório de seminário da comissão de reforma do sistema educativo. Lisboa: Estrutura e Planeamento do Ministério da Educação, 1988, p. 53-102.

FOSTER, P. The purposes of observational research. London: Paul Chapman, 1996. 
GOROSTIAGA, J.; TELLO, C. Globalización y reforma educativa en América Latina: un análisis inter-textual. Revista Brasileira de Educação, 16, 363-388, 2011.

KRAWCZYK, N. A gestão escolar: Um campo minado... Análise das propostas de 11 municípios brasileiros. Educação \& Sociedade, XX, 112-149, 1999.

A sustentabilidade da reforma educacional em questão: A posição dos organismos internacionais. Revista Brasileira de Educação, 19, 43-62, 2002.

O PDE: novo modo de regulação estatal? Cadernos de Pesquisa, 38, 797815. Retrieved from http://www.scielo.br/scielo.php?script=sci doi:10.1590/S01005742008000300013, 2008.

LIMA, A. Democracia e democratização: As possíveis contribuições da escola pública estatal. Paper presented at the Seminário Nacional-Estado e políticas sociais no Brasil. Cascavel, 2005.

LIMA, L. Modelos de organização das escolas básica e secundária. In J. Formosinho (Ed.), A gestão do sistema escolar: relatório de Seminário/comissão de reforma do sistema educativo. Lisboa: Gabinete de Estrutura e Planeamento do Ministério da Educação, 1998, p 149-195.

A escola como organização e a participação na organização escolar - Um estudo da escola secundária em Portugal (1974-1988). Doutoramento, Universidade do Minho, Braga, 1991.

MARINIS, P. Comunidade, globalização e educação: Um ensaio sobre a descoversação do social. Pró-posições, 19, 19-45, 2008

MARTINS, A. Gestão e autonomia escolar: um estudo comparado Brasil/Portugal. Revista Brasileira de Educação, 16, 69-98. Retrieved from http://www.scielo.br/scielo doi:10.1590/S1413-24782011000100005, 2011.

NEVES, J. L. (1996). Pesquisa qualitativa - Características, usos e possibilidades. Cadernos de Pesquisa em Administração, 1, 1-5, 1996.

TORRES, L., ; PALHARES, J. Estilos de liderança e escola democrática. Revista Lusófona de Educação, 77-99, 2009.

VASQUES, M. Metodologia da pesquisa científica. São Paulo: Uninove, 2008. 
PORTUGAL. Lei no 46/1986. Dispõe sobre Lei de Bases da Educação Nacional portuguesa. Lisboa: MEC, 1986.

Constituição da República Portuguesa/1976 - revisada/2005 (1976). Lisboa: Presidência da República, 1976.

Decreto-lei, que trata da organização da gestão nas escolas portuguesas, Lisboa, 2008. 